\title{
IMPLEMENTASI E-COMMERCE PADA KIOS KELINCI PETANI MENGGUNAKAN CONTENT MANAGEMENT SYSTEM (CMS) UNTUK MENINGKATKAN PENJUALAN DENGAN METODE BUSINESS MODEL CANVAS (BMC)
}

\author{
Muhamad Alfi Fauzan', Yuliazmi Yuliazmi ${ }^{2 *}$ \\ ${ }^{1.2}$ Fakultas Teknologi Informasi, Sistem Informasi, Universitas Budi Luhur, Jakarta, Indonesia \\ Email: ${ }^{1}$ alfifauzan478@ gmail.com, ${ }^{2 *}$ yuliazmi@budiluhur.ac.id \\ $(*$ : coressponding author)
}

\begin{abstract}
Abstrak-Kelinci Petani adalah Kios yang didirikan pada tahun 2017, Kios Kelinci Petani adalah Kios yang menjual kebutuhan untuk hewan peliharaan, Kios Kelinci Petani menjual kebutuhan hewan peliharaan dengan cara berjualan konvensional dan menggunakan marketplace. Tidak hanya menjual kebutuhan hewan saja, Kios ini juga menyediakan jasa grooming khusus untuk kelinci. Hal ini tentu saja menjadi nilai lebih pada Kios Kelinci Petani dalam memberikan layanan kepada pelanggan Kios Kelinci Petani. Masalah yang terjadi pada Kios Kelinci Petani yaitu sulit untuk melakukan promosi produk yang akan dijual pada jangkauan pemasaran yang lebih luas, dan sulit untuk memasarkan produk yang tidak terjual atau persediaan lama. Di zaman yang serba teknologi ini penulis melakukan penelitian pada masalah tersebut dan mendapat solusi untuk memecahkan masalah tersebut dengan menggunakan sistem e-commerce menggunakan Content Management System (CMS) yaitu tools dari wordpress sebagai solusi pemecahan dari masalah yang terjadi. Dalam penelitian ini, penulis memakai metode Business Model Canvas (BMC) serta menyiapkan strategi pemasaran menggunakan Search Engine Optimization (SEO) untuk mencakup pasar yang lebih luas untuk calon pelanggan pada Kios Kelinci Petani. Sebagai hasil dari penelitian ini, Kios Kelinci Petani memiliki sistem berupa website e-commerce yang memungkinkan Kios Kelinci Petani untuk memperluas pasar dan meningkatkan penjualan di seluruh Indonesia.
\end{abstract}

Kata Kunci: Teknologi, Pemasaran, Search Engine Optimization, E-Commerce, Kelinci Petani

\begin{abstract}
Kelinci Petani is a shop that was founded in 2017, the Kelinci Petani shop is a shop that sells necessities for pets, the Kelinci Petani shop sells pet needs by selling conventionally and using a marketplace. Not only selling animal needs, but this shop also provides special grooming services for rabbits. This is of course an added value to the Kelinci Petani shop in providing services to the Kelinci Petani shop customers. The problem that occurs at the Kelinci Petani Store is that it is difficult to promote products that will be sold to a wider marketing range, and it is difficult to market products that are not sold or are in old inventory. In this technological era, the author researched this problem and found a solution to solve the problem by using an ecommerce system using a Content Management System (CMS), namely tools from WordPress as a solution to the problem that occurred. In this study, the author uses the Business Model Canvas (BMC) method and prepares a marketing strategy using Search Engine Optimization (SEO) to cover a wider market for potential customers at the Kelinci Petani shop. As a result of this research, the Kelinci Petani store has a system in the form of an e-commerce website that allows the Kelinci Petani store to expand its market and increase sales throughout Indonesia.
\end{abstract}

Keywords: Technology, Markeing, Search Engine Optimization, E-Commerce, Kelinci Petani

\section{PENDAHULUAN}

Dengan berkembangnya teknologi informasi, semakin banyak orang yang memahami pentingnya fungsi IT dalam menunjang bisnis, namun hanya sedikit perusahaan, CV atau kios yang menggunakannya. Internet dan Web adalah contoh teknologi yang menyediakan berbagai cara untuk menyelesaikan pekerjaan anda dengan cepat dan mudah. Misalnya, ini disebut penjualan elektronik atau perdagangan elektronik. Aplikasi E-Commerce yang dibangun di atas kios dan agen lainnya memungkinkan pelanggan dan konsumen untuk menjangkau secara langsung tanpa mengunjungi kios. [1]

E-commerce saat ini menjadi alternatif yang menjanjikan karena dapat memberikan banyak kemudahan baik bagi penjual maupun pelanggan dalam melakukan atau membeli suatu bisnis. [2]

Kios Kelinci Petani adalah Kios yang menjual berbagai macam kebutuhan hewan. Kios ini berdomisili di daerah Tangerang Selatan tepatnya di daerah perumahan maharta. Kios ini sudah menggunakan marketplace, namun biaya yang harus dikeluarkan untuk fitur layanan yang dimana fungsinya untuk meningkatkan penjualan dan kepercayaan pelanggan memberatkan pemilik Kios ditambah dampak dari pandemi ini semakin membebankan karena sepi pengunjung yang datang langsung ke Kios.

Sebagai salah satu solusi menjawab masalah tersebut, penulis memberikan solusi dengan membuat sistem penjualan yang berbasis situs web dengan konsep e-commerce untuk memudahkan konsumen berbelanja secara online dengan baik juga memberikan strategi pemasaran agar pemilik tidak bergantung ke marketplace yang memberatkan biaya dari fitur layanan dibandingkan memiliki website e-commerce sendiri. 
Penelitian ini bertujuan untuk merancang serta membangun sistem e-commerce pada Kios Kelinci Petani sebagai pengembangan sistem penjualan agar semakin meningkat, mempermudah dalam hal penyajian informasi yang dibutuhkan secara akurat, memudahkan penjual dan pembeli untuk mengakses website dari mana saja dan kapan saja. Beberapa studi literatur yang terkait, antara lain: pertama [3] menjelaskan pembahasan tentang masalah ini mungkin bukan informasi terbaik yang dimiliki pelanggan mengenai detail produk dan produk terbaru. Tidak ada sarana komunikasi yang tersedia untuk memungkinkan pelanggan memesan produk yang dijual. Selain itu karena sistem penjualannya masih konvensional, pembeli diharuskan datang langsung ke Kios, bagi pelanggan yang jauh dari Kios akan kesulitan. Kedua [4] menjelaskan tentang permasalahan Pengelohan data pada Space Vapor Store belum terolah dengan baik, masih membutuhkan waktu cukup lama, memberikan informasi masih salah karena kesalahan yang mungkin dilakukan manusia. Tujuan dari penelitian ini untuk memecahkan permasalahan yang ada di Space Vapor Store dengan menggunakan sistem informasi penjualan yang akan membantu proses pekerjaan tersebut menjadi lebih baik dari sebelumnya. Ketiga [5] melakukan penelitian dengan mencari pengaruh Search Engine Optimization (SEO) dan riset kata kunci terhadap pendapatan Kios online.

\section{METODOLOGI PENELITIAN}

Metodologi Penelitian adalah suatu langkah-langkah dalam penelitian yang dilakukan dimulai dari menentukan metodologi yang akan digunakan dalam menyelesaikan masalah dalam penelitian tersebut [6]. Berikut ini adalah langkah - langkah metode yang peneliti lakukan:

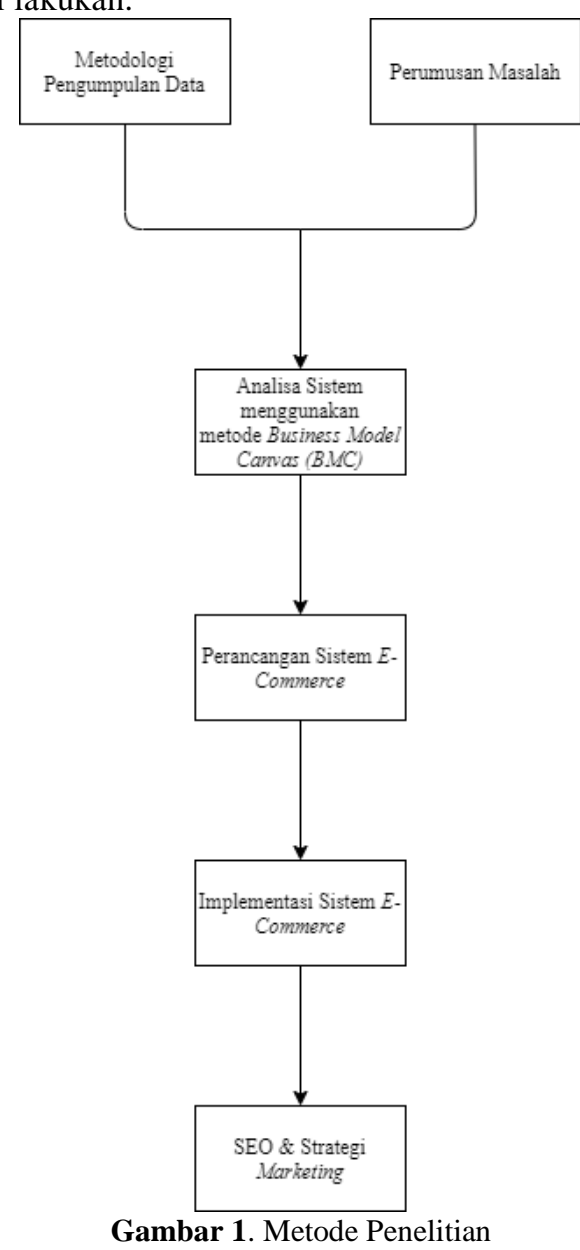

Bisa dilihat pada Gambar 1, tahap pertama yang dilakukan adalah metodologi pengumpulan data dengan cara melakukan studi lapangan secara langsung yaitu wawancara, observasi, dan studi dokumen, lalu melakukan studi literatur untuk belajar tentang penelitian sebelumnya pada subjek yang sama seperti membaca dan membuat karya ilmiah akhir, buku dan jurnal yang memiliki ISSN dan memanfaatkan google scholar untuk melakukan pencarian jurnal, setelah itu melakukan perumusan masalah dengan cara mengidentifikasi beberapa masalah yang ada pada Kios Kelini Petani. Selanjutnya penulis melakukan analisis sitem menggunakan metode Business Model Canvas (BMC) dan melakukan perancangan sistem E-Commerce dengan menggunakan activity diagram, use case diagram, 
rancangan layar menggunakan aplikasi adobe $x d$ dan draw.io untuk hasil yang lebih optimal, lalu penulis melakukan implementasi sistem e-commerce menggunakan dua tahapan yaitu eksplorasi dan implementasi dengan content management system di wordpress serta penulis melakukan testing terlebih dahulu di localhost agar sistem lebih baik dan juga terhindar dari bug pada sistem, kemudian menggunakan hosting dan domain untuk tahap akhir $e$ commerce. Tahapan terakhir yaitu penulis melakukan implementasi search engine optimization dan hasil yang didapat adalah Kios Kelinci Petani mampu bersaing di mesin pencari sehingga menambah kunjungan, meningkatkan penjualan serta akan lebih dikenal luas oleh masyarakat dan juga peneliti melakukan strategi marketing menggunakan media sosial facebook dan instagram supaya para pelanggan mengetahui informasi produk terbaru yang ada pada Kios Kelinci Petani.

\section{HASIL DAN PEMBAHASAN}

\subsection{Business Model Canvas}

Business Model Canvas adalah metode yang digunakan untuk mengatur dan mengelola strategi bisnis yang berbentuk visual dan dapat dipahami oleh pengguna [6]. Berikut adalah business model canvas pada Kios Kelinci Petani pada Gambar 2:

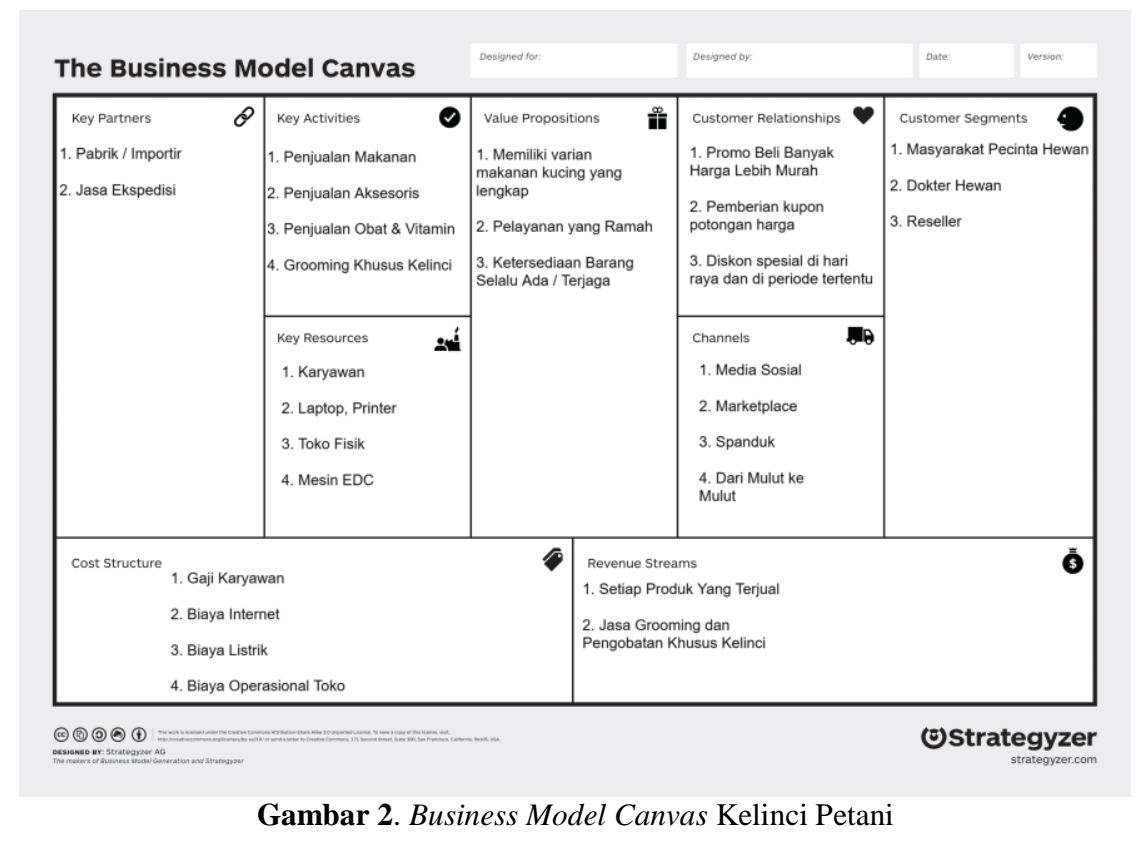

Komponen - komponen yang terdapat pada bussines model canvas beserta deskripsinya yang telah di analisis pada Kios Kelinci Petani:

a. Value Propotitions adalah nilai yang ditawarkan oleh Kios Kelinci Petani kepada pelanggan yaitu berupa varian makanan kucing yang lengkap, pelayanan yang ramah, dan ketersediaan barang selalu ada (terjaga).

b. Customer Segment adalah target pasar yang dituju oleh Kios Kelinci Petani mulai dari masyarakat pecinta hewan, dokter hewan dan reseller.

c. Channel adalah sarana untuk mendistribusikan atau mempromosikan produk pada Kios Kelinci Petani dengan menggunakan media sosial, marketplace, spanduk dan yang terakhir yaitu dari mulut ke mulut.

d. Customer Relatonships adalah menjaga hubungan antar melanggan agar pelanggan datang kembali ke Kios Kelinci Petani dengan cara memberikan promo beli banyak harga lebih murah, kupon potongan harga, diskon spesial di hari raya dan di periode tertentu.

e. Revenue Streams adalah pendapatan yang didapat oleh Kios Kelinci Petani dengan cara menjual produk dan jasa grooming dan pengobatan khusus untuk kelinci.

f. Key Activities adalah semua kegiatan atau aktivitas utama yang dilakukan Kios Kelinci Petani yaitu melakukan penjualan makanan, aksesoris, obat dan vitamin serta melakukan grooming khusus untuk kelinci.

g. Key Resources adalah hal yang paling penting yang harus Kelinci Petani miliki agar key activities bisa dijalankan dan value propositions bisa diberikan pada pelanggan, key resources pada Kios Kelinci Petani berupa sumber daya manusia (karyawan), aset fisik untuk melakukan penjualan produk, laptop dan printer, dan mesin EDC. 
h. Key Partners yaitu adalah entitas-entitas yang mendukung usaha tersebut yang dibutuhkan oleh Kios Kelinci Petani yaitu pabrik (importir), dan jasa ekspedisi.

i. Cost Structure adalah rincian biaya yang harus dikeluarkan oleh Kios Kelinci Petani untuk melakukan key activities. Berikut dana yang harus dikeluarkan Kios Kelinci Petani setiap bulannya seperti gaji karyawan, biaya internet, biaya listrik dan juga biaya operasional Kios.

\subsection{Proses Bisnis Usulan}

Activity Diagram menggambarkan alur kerja atau operasi yang menguntungkan sistem atau proses bisnis yang sedang dilakukan. [7].

a. Activity Diagram Proses Pemesanan Produk

Activity Diagram proses pemesanan produk menggambarkan interaksi pelanggan dengan sistem Kios Kelinci Petani. Mulai dari pelanggan mengunjungi halaman website Kios Kelinci Petani, lalu memilih dan menentukan produk yang ada di website Kios Kelinci Petani sampai ke proses pelanggan melakukan proses pembayaran dan konfirmasi pembayaran pada website Kios Kelinci Petani. Activity Diagram proses pemesanan produk bisa dilihat pada Gambar 3:

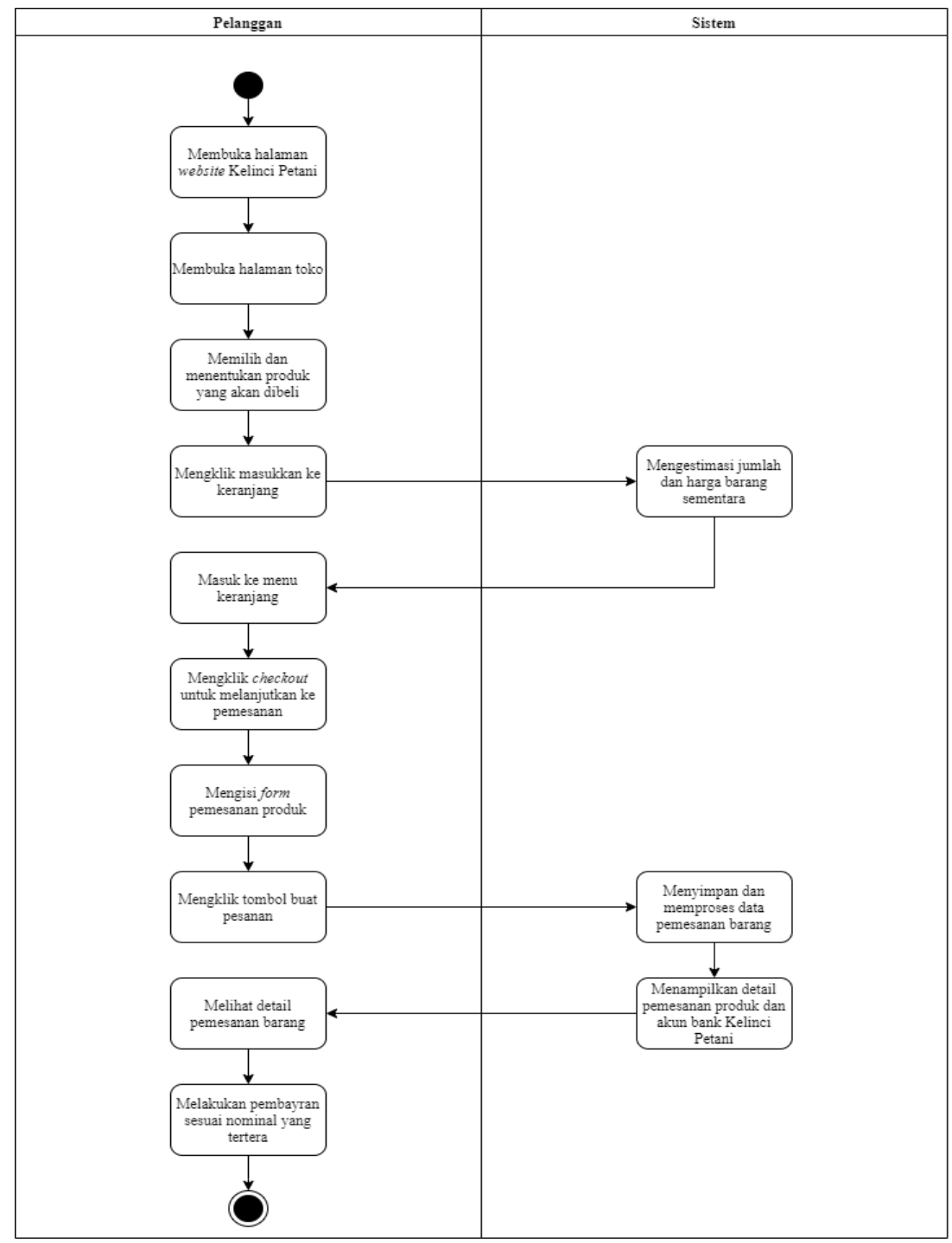

Gambar 3. Activity Diagram Proses Pemesanan Produk

b. Activity Diagram Proses Pembayaran Produk

Activity Diagram proses pembayaran menjelaskan alur pembayaran pada website Kios Kelinci Petani. Pelanggan melakukan proses pembayaran dengan cara mentransfer sesuai nominal yang tertera di website. Setelah pelanggan menyelesaikan pembayaran pelanggan dapat melakukan proses konfirmasi pembayaran dengan mengklik 
menu konfirmasi pembayaran dan mengisi data-data di halaman konfirmasi pembayaran. Lalu pelanggan mengklik submit. Setelah itu sistem akan menyimpan dan memproses konfirmasi pembayaran. Activity Diagram proses pembayaran produk bisa dilihat pada Gambar 4:

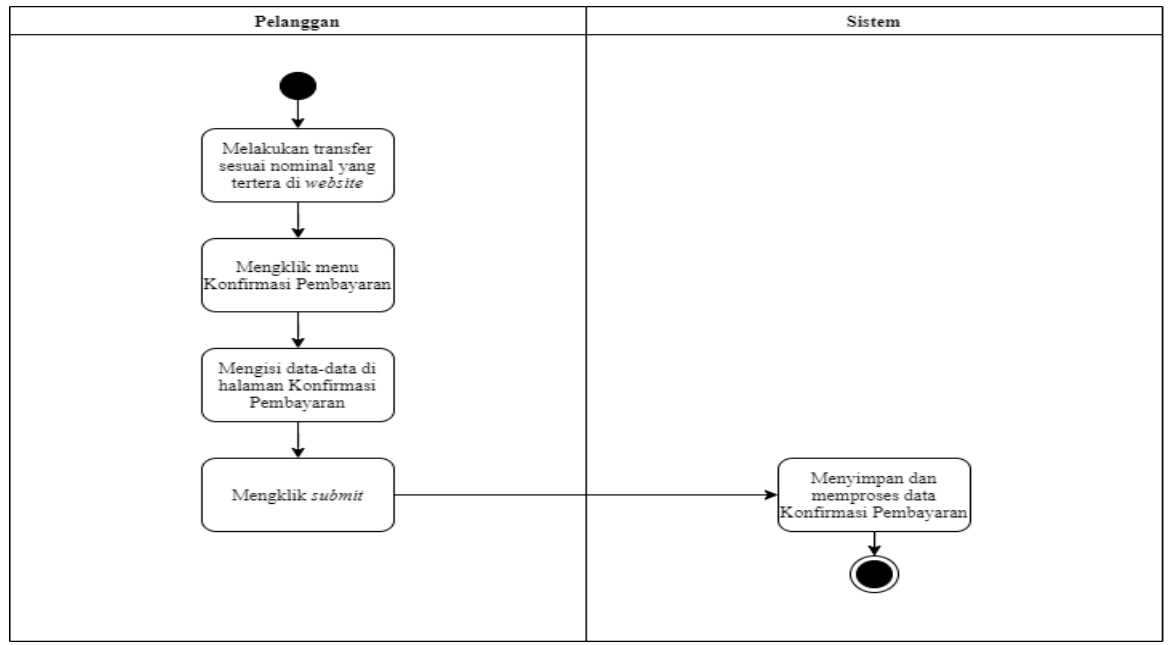

Gambar 4. Activity Diagram Proses Pembayaran Produk

\subsection{Use Case Diagram}

Use Case Diagram adalah model kerja (perilaku) dari sistem informasi yang dibuat. Sebuah use case menggambarkan interaksi antara satu atau lebih aktor dan sistem informasi yang dihasilkan. Dengan kata lain, use case digunakan untuk mengetahui apa saja kapabilitas suatu sistem informasi dan siapa yang berhak menggunakan kapabilitas tersebut. [7]. Use Case Diagram yang di implementasikan pada website Kios Kelinci Petani terdiri dari pelanggan, pegawai, pemilik Kios dan sistem yang akan melakukan interaksi untuk mengoperasikan website Kios Kelinci Petani dan akan mencetak laporan yang diperlukan untuk pengambilan keputusan pihak Kios Kelinci Petani. Use Case Diagram bagian 1 bisa dilihat pada Gambar 55 dan Gambar 6:
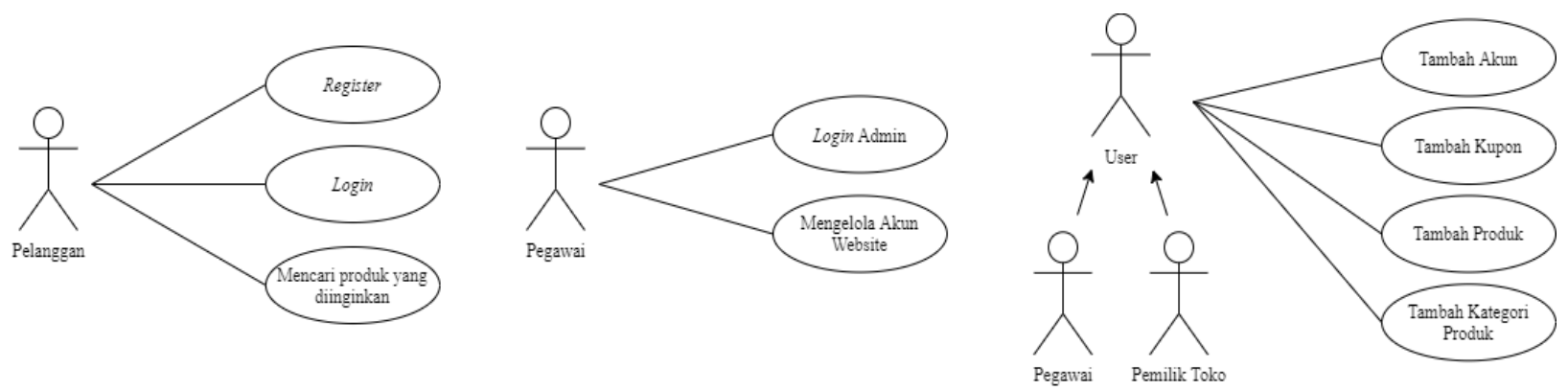

Gambar 5. Use Case Diagram Bagian 1 Kelinci Petani
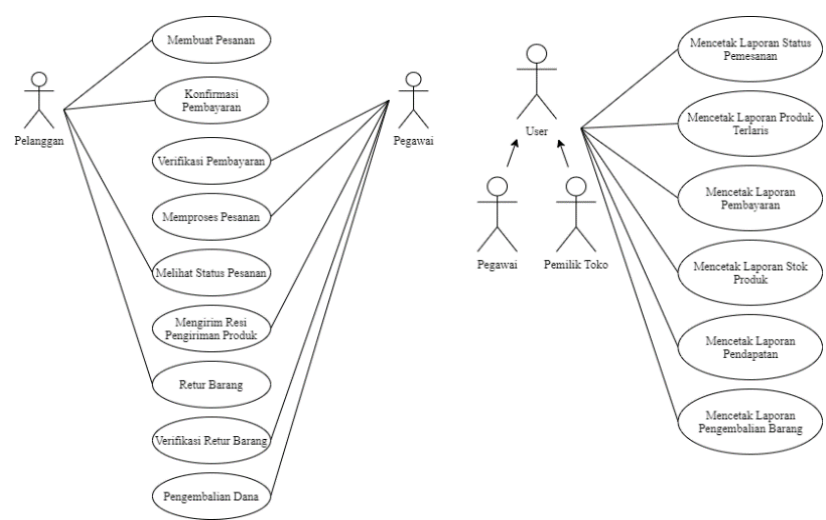

Gambar 6. Use Case Diagram 2 Kelinci Petani 


\subsection{Rancangan Layar}

Rancangan Layar adalah prototipe desain tampilan awal untuk situs web yang berfungsi sebagai antarmuka pengguna ke suatu sistem, juga dikenal sebagai antarmuka pengguna. [8].

a. Rancangan Layar Beranda

Rancangan layar beranda ini berfungsi sebagai halaman beranda pelanggan pada website Kios Kelinci Petani, halaman ini langsung bisa diakses ketika pelanggan mengakses website Kios Kelinci Petani. Rancangan Layar Beranda bisa dilihat pada Gambar 7:

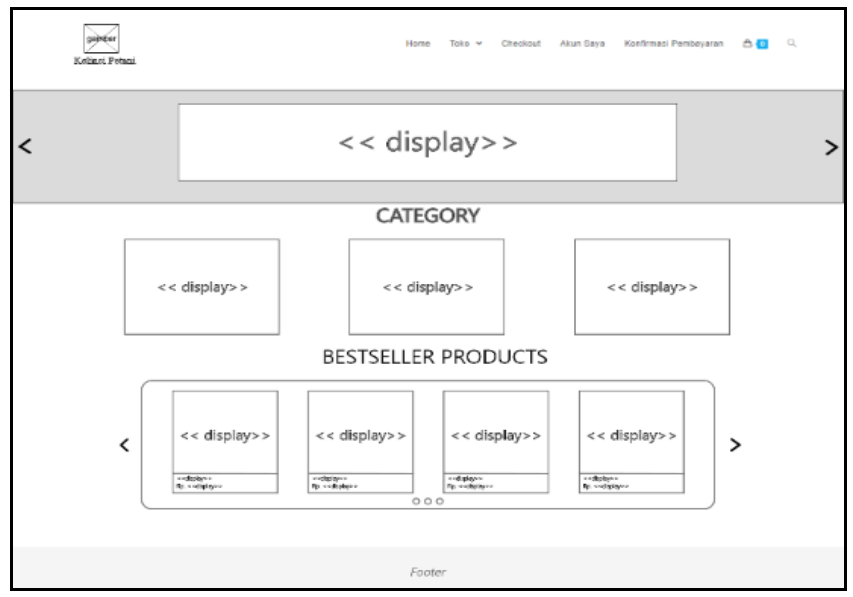

Gambar 7. Rancangan Layar Beranda

b. Rancangan Layar Checkout

Rancangan layar checkout ini berfungsi sebagai halaman pelanggan untuk melanjutkan pesanan ke checkout dan melakukan pembayaran pesanan produk yang sudah dibeli oleh pelanggan. Rancangan Layar Checkout bisa dilihat pada Gambar 8:

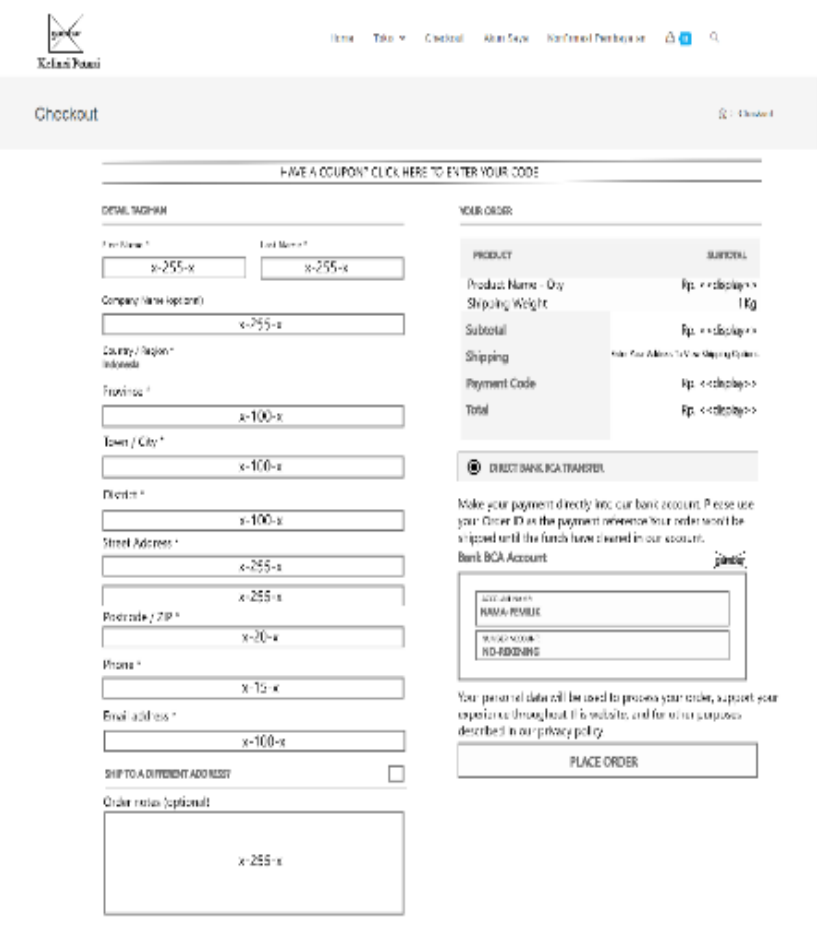

Gambar 8. Rancangan Layar Checkout 
c. Rancangan Layar Konfirmasi Pembayaran

Rancangan layar konfirmasi pembayaran ini berfungsi sebagai halaman pelanggan untuk melakukan konfirmasi pembayaran pada website Kios Kelinci Petani dengan meng-upload bukti pembayaran yang sah berupa foto fisik atau screenshot. Rancangan Layar Konfirmasi Pembayaran bisa dilihat pada Gambar 9:

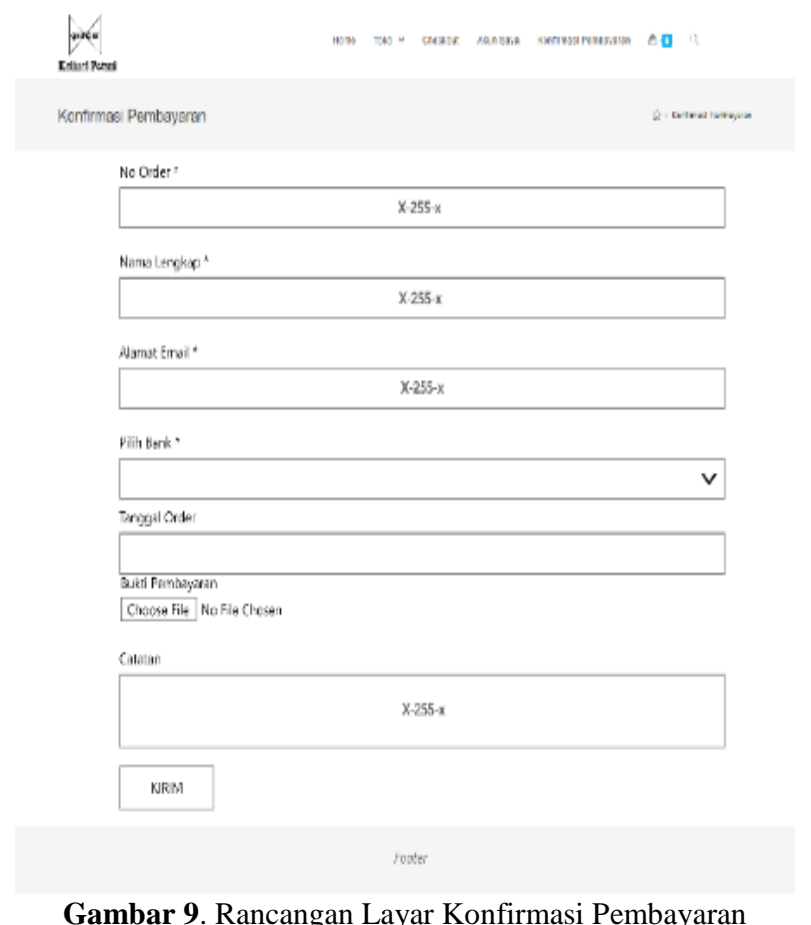

d. Rancangan Layar Retur Barang

Rancangan layar Retur Barang ini berfungsi sebagai halaman pelanggan untuk melakukan retur barang pada website Kios Kelinci Petani dengan meng-upload foto produk yang sudah dipesan sebelumnya. Rancangan Layar Retur Barang bisa dilihat pada Gambar 10:

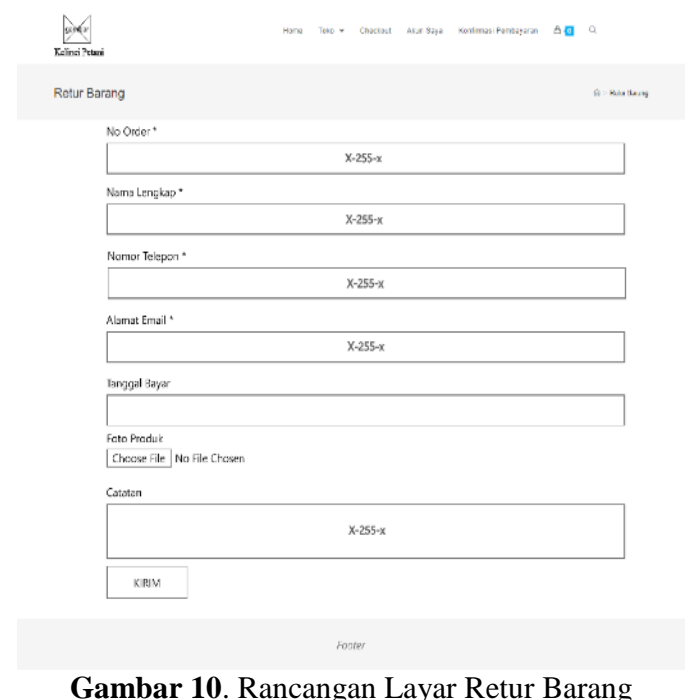

\subsection{Search Engine Optimization}

Search Engine Optimization (SEO) adalah metode yang digunakan untuk mendapatkan manfaat di mesin pencari yang match dengan kata kunci yang ada pada situs web. [9] Berikut ini adalah langkah-langkah untuk mengoptimasi SEO dengan menggunakan tools Yoast SEO pada website Kios Kelinci Petani: 
a. Membuat kata kunci penelusuran yang berkaitan dengan produk dan membuat judul SEO, slug, serta deskripsi meta agar mudah ditemukan saat pelanggan mencari produk yang telah dilakukan optimasi SEO. Optimasi SEO bisa dilihat pada Gambar 11:

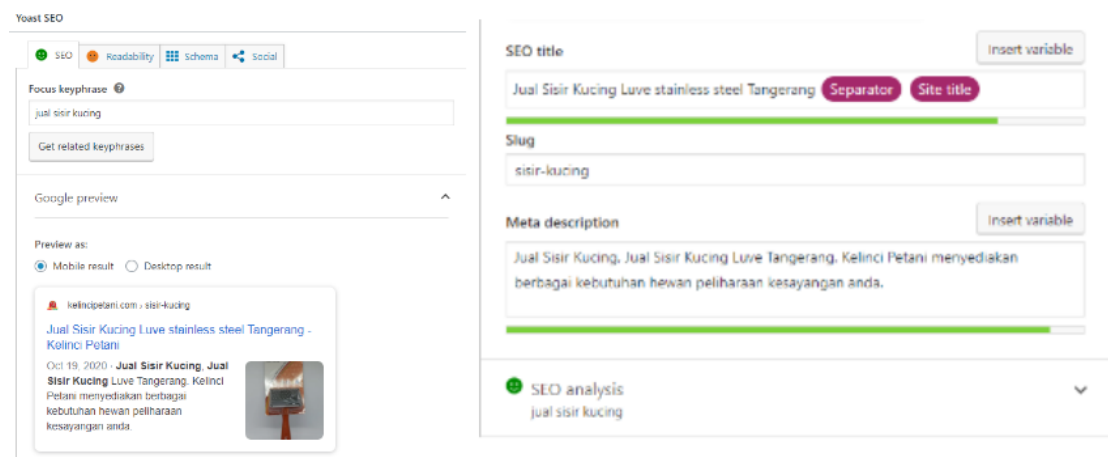

Gambar 11. Judul SEO, Kata Kunci Penelusuran, Slug dan Deskripsi Meta

b. Hasil penelusuran yang didapatkan ketika telah melakukan optimasi SEO. Hasil penelusuran tersebut didapatkan pada tanggal 30 januari. Hasil SEO bisa dilihat pada Gambar 12:

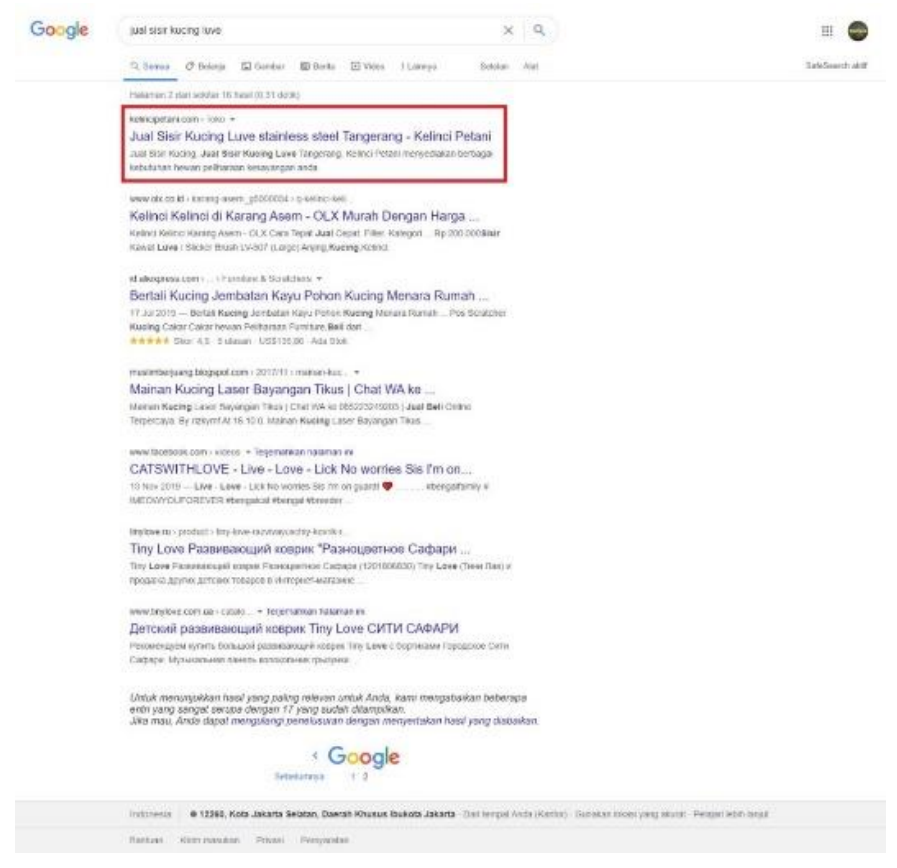

Gambar 12. Hasil Penelusuran di Google

\subsection{Strategi Pemasaran}

Strategi pemasaran melibatkan pemilihan dan analisis pasar sasaran, yaitu sekelompok orang yang ingin dijangkau perusahaan, untuk menciptakan bauran pemasaran yang tepat untuk memenuhi pasar sasaran [10]. Strategi pemasaran yang lakukan di Kios Kelinci Petani menggunakan website dengan cara meningkatkan kualitas konten di dalam website dan rajin menerbitkan produk baru agar pengunjung website serta menggunakan media sosial facebook dan instagram.

\section{KESIMPULAN}

Kesimpulan dari implementasi yang menggunakan Content Management System (CMS) ini yaitu untuk memperluas pemasaran dan meningkatkan penjualan pada Kios Kelinci Petani, sehingga pelanggan yang berada jauh dari Kios tetap dapat mengetahui produk yang ditawarkan oleh Kios Kelinci Petani khususnya untuk diluar daerah Tangerang serta dengan Kios online (e-commerce) yang fleksibel, pemilik dapat mengetahui cara 
INDONESIA JOURNAL INFORMATION SYSTEM (IDEALIS)

Volume 4, Nomor 2, Bulan 2021

ISSN 2684-7280 (online)

Halaman 223-231

available online at http://jom.fti.budiluhur.ac.id/index.php/IDEALIS/index

meningkatkan penjualan karena diharapkan dapat berjualan secara efektif dengan menggunakan Kios online yang dapat membuat pelanggan membeli dimana saja dan kapan saja tanpa terhalang tempat.

\section{DAFTAR PUSTAKA}

[1] E. Haerulah and S. Ismiyatih, “Aplikasi e-commerce penjualan souvenir pernikahan pada Kios ' XYZ,"” Jurnal Prosisko, vol. 4, no. 1, pp. 43-47, 2017.

[2] S. M. Maulana, H. Susilo, and Riyadi, "Implementasi E-Commerce Sebagai Media Penjualan Online," Jurnal Administrasi Bisnis, vol. 29, no. 1, pp. 1-9, 2015.

[3] M. D. S. Ananda and I. Novita, "Sistem Informasi Penjualan Batik Berbasis Website Pada Kios Kencana Ayu," Jurnal IDEALIS, pp. 28-32, 2015.

[4] R. Ramadhan et al., "Perancangan E-commerce Untuk Meningkatkan Penjualan Pada Space Vapor Store", vol.3, no.1, pp. 152-156, 2018.

[5] A. Sofyan, E. Ferdianto, R. Rahmawati, and R. K. Aldi, "Pengaruh Search Engine Optimization (Seo) Dan Riset Kata Kunci Terhadap Pendapatan Kios Online," Indonusa Conference Technology Social Science, vol. 1, no. 1, pp. 351-356, 2019.

[6] F. Ramadhan and L. Fajarita, "Implementasi Rancangan E-Commerce Pada Surya Timur Collection Dengan Metode Business Model Canvas (BMC) Berbasis Content Management System (CMS)," Jurnal IDEALIS, vol. 3, no. 1, pp. 251-259, 2020.

[7] G. Urva, H. F. Siregar, J. Prof, M. Y. Kisaran, and S. Utara, "Pemodelan UML E- Marketing Minyak Goreng", Jurnal Teknologi dan Sistem Informasi, vol. 1, no. 2, pp. 92-101, 2015.

[8] E. Revsie Akbar and H. Irawan, "Analisis dan Implementasi E-Commerce Menggunakan CMS Wordpress Pada Queenita Classic", Jurnal IDEALIS, vol. 4, no. 1, pp. 107-116, 2021.

[9] L. Fitria and D. Anubhakti, "Sistem Penjualan Berbasis E-Commerce Menggunakan Metode Business Model Canvas Untuk Mendukung Penjualan Pada PT. Akses", Jurnal IDEALIS, vol. 2, no. 6, pp. 101-106, 2019.

[10] E. D. Wawolumaya, D. L. Tampi, and J. J. Rogahang, "Analisis Strategi Pemasaran Dalam Upaya Meningkatkan Volume Penjualan Pada Rose Collection Manado," Productivity, vol. 1, no. 2, pp. 134-141, 2020. 